\title{
CHRONOTYPE IDENTIFICATION OF BULGARIAN SPORTS STUDENTS
}

\author{
Maria Zaharinova, Nikolay Zaekov, \\ Krassimir Rankov, Milena Nikolova
}

\begin{abstract}
The aims of this study were to identify sports students' chronotype in Sofia, Bulgaria and to determine the subjective feeling for right training time. The experimental sample consisted of 104 male and female students attending various study programs at faculties of the National Sports Academy "Vassil Levski" in Sofia during the academic year 2016/2017. The participants' chronotype was identified by standardized questionnaire (Horn \& Ostberg Morningness and Eveningness questionnaire, 1976). The results showed that 61 students tended to be the intermediate chronotype, moderate morning chronotype was identified in 26 students, and moderate evening chronotype was identified in 17 students. Definitely morning and definitely evening types were not identified.

Most of the subjects defined themselves, according question 19, as definitely morning $(n=22)$ or definitely evening type $(n=21)$, but the questionnaire assigns them as intermediate or moderate morning and evening types. More than half of the students who subjectively considered themselves to be an evening type suppose that the training is not done in a suitable time for them. Due to the significant differences between subjective self-identification by the persons surveyed and the determination of the chronotype through a questionnaire, the following conclusions can be drawn: 1) If possible, always make a determination of the athlete's chronotype through a questionnaire; 2) Coaches should always take into account the chronotype of athletes when they arrange the training schedules.
\end{abstract}

Keywords: Chronotype, athletes, training schedules.

\section{Introduction}

The study of biological rhythms mechanisms (with different period length), the possible disruptions of these rhythms and the consequences is called Chronobiology. The scientific interest in human circadian rhythms (CRs) began in 1938 when Nathaniel Kleitman spent a month in a cave. He demonstrated that under constant dim light conditions sleep did not retain its 24 - hour pattern (Wirz - Justice'07). In the last twenty years the interest in the study of individual typology has increased, as a way to understand the body's biochemical, physiological, psychological functions and performance (mental and sports). Chronotype is a behavioral phenotype that reflects human beings individual CRs (Levandovski et al.'13; Roenneberg et al.'07). These rhythms are internally driven biological fluctuations that oscillate with a period near 24 hours (Kunorozva'11). They are capable to synchronize to environmental photic and non-photic cues (for example physical exercise). Typically, there are large inter-individual variations in the phases of the rhythms due to the fact that rhythms are not exactly 24-hours; which classifies humans as morning types, intermediate types and evening types. Morning types (MT or "larks") wake up easily early in the morning and are more active in the early hours of the day. They prefer to go to bed early in the evening and cannot stay awake after midnight. Evening types (ET or "owls"), in contrast, are more active in the afternoon or in the evening and find it difficult to wake up early in the morning. In the middle of the spectrum between MT and ET there is one more chronotype - intermediate (IT) (Adan et al.'12) or neutral chronotype (NT). This chronotype has balanced performance and other characteristics during the day and there is no preference in any part of the day (Vancova \& Pivovarnicek'16). The same classification is used by Horne \& Ostberg (1976), Reilly et al. (2007), Rae et al. (2015), Lastella et al. (2016), Vankova \& Pivovarnicek (2016). Studies in the field of chronotype distribution among the general adult population (19-31 years) showed that most individuals are ITs (Adan \& Natal'02; Roenneberg et al.07; Vancova \& Pivovarnicek'16). Study of association between physical exercise and CRs is a recent and emerging area of research in the field of sports biochemistry, physiology and medicine. Many laboratories around the world are working in this area (Research Unit for Exercise Science and Sports Medicine, University of Cape Town, South Africa; Central Queensland University, Appleton Institute for Behavioral Science, Australia; Department of Physical Education and Sports, Matej Bel University, Slovakia; Department of Kinesiology, University of North Texas, USA). Chronotypes of sports people have been assessed mainly for their effects on aerobic and anaerobic performance. There is evidence that diurnal variations exist with best performance in the evening (reviewed in Drust et al.05; 
Kline et al.'07; Chtourou et al.'12). Recent studies showed that professional athletes tend to be more morning oriented (Lastella et al.'10; Rae et al.'15) and also that the time of the entrained awakening reflects the internal biological clock (Facer-Childs \& Brandstaetter, 2015). Our observations showed that in Bulgaria there are studies on human CRs in the literature but in connection with different medical conditions, professions like professional soldiers, pilots and in the field of CR and sports it deals with jet lag (reviewed in Alexandrov'98; Kareva'12; Slanchev'14). For that reason, we considered that it would be beneficial to take up basic research in the area of CRs. Our aims were to identify sports students chronotype and to determine the subjective feeling for right training time. As the CRs of many physiological factors have been shown to differ in MTs and ETs (Baehr et al'00; Hill et al'.88) it would appear logical to believe that chronotype might affect diurnal variation in sport performance and a person's preferred time-of-day for exercise and sport participation.

\section{Methodology}

A total of 104 physically active students between 20 and 31 years of age (69 male and 35 female students) from different faculties volunteered to participate in our study. Chronotype was assessed by the standardized Horne and Ostberg Morningness - Eveningness Questionnaire (MEQ). The MEQ is a self-assessment questionnaire which contains 19 closed questions and classifies humans according to their preference toward performing certain ac-

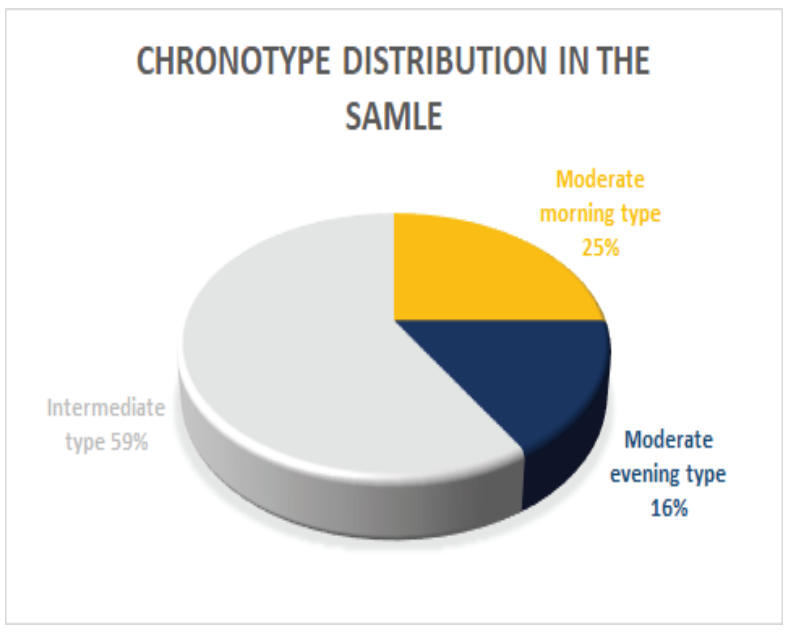

A

Fig.1 Chronotype (A) and gender (B) distribution in the sample tivities in particular time of day. Each answer (a, b, c, $\mathrm{d}$ and sometimes e) has given number of points (from 16 to 86). Higher number of points determines morning oriented person and lower numbers of points indicates an evening chronotype. Initially we counted points according to answers after that we assess concrete chronotype according to MEQs rating scale with five options:

- Definitely morning chronotype - DMT (70-86 points)

- Moderate morning chronotype - MMT (59-69 points)

- Intermediate chronotype - IT (42-58 points)

- Moderate evening chronotype - MET (3141 points)

- Definitely evening chronotype - DET (1630 points)

We also compare the assessed chronotype with self-assessment made in question 19.

\section{Results}

We identified 61 students to be IT according to MEQ scores (59\%). 26 students were identified as Moderate morning chronotype (25\%) and Moderate evening type was assessed in 17 students $(16 \%)$ as shown in figure 1A. The mean score for all students was 50.76. Our sample consisted of males $(65 \%)$ and females (34\%) as displayed in figure 1B. Figures 2 and 3 represent the distribution of different chronotypes by age. Females showed tendency to be more morning oriented than males.

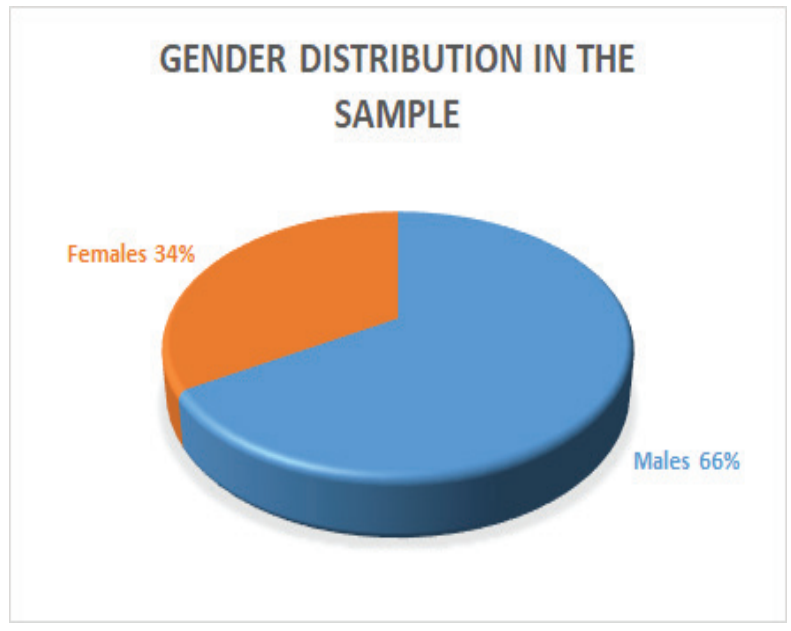

$B$

$B$

(n) 
Distribution of Moderate morning type by

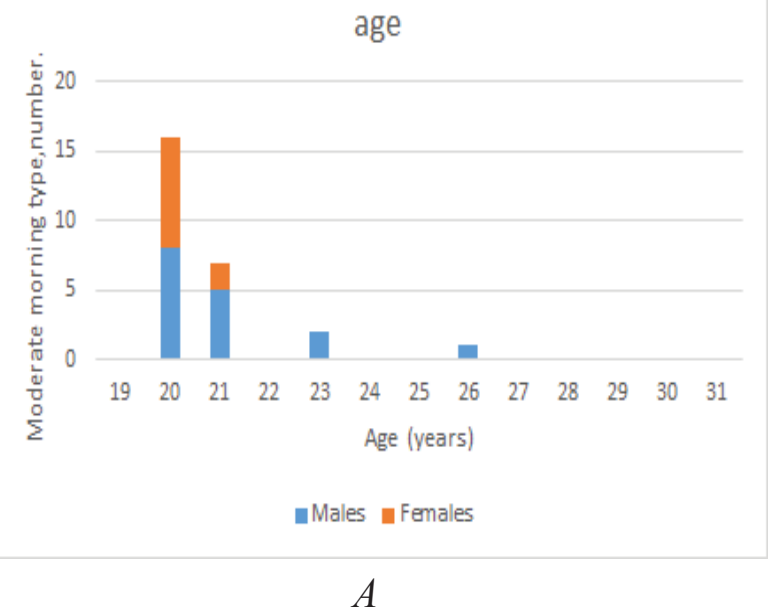

Distribution of Moderate eveninig type by age

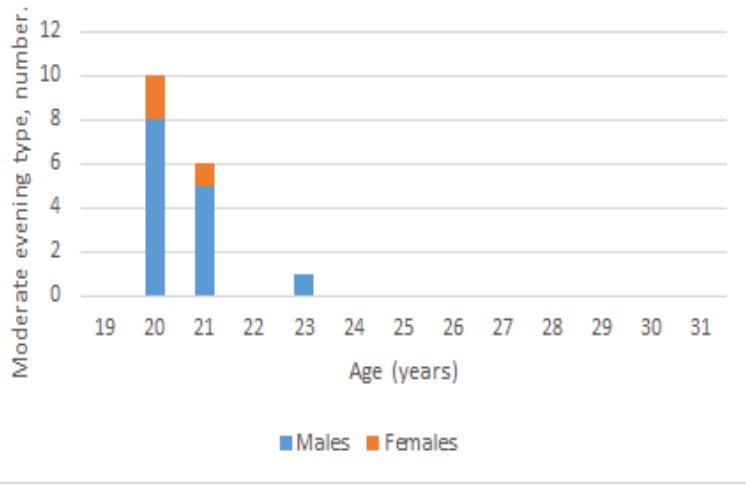

$B$

Fig. 2 Distribution of MMT (A) and MET (B) (according to MEQ scores) by age

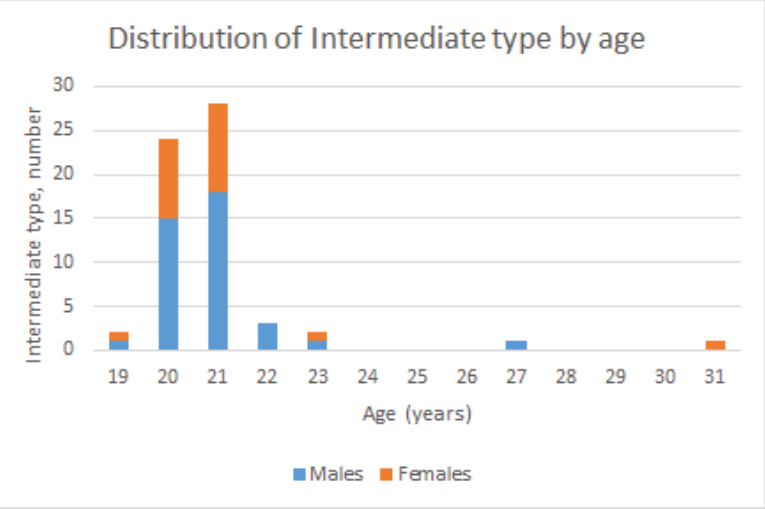

Fig.3 Chronotype distribution by age (intermediate type - according to MEQ scores)

Then we compared the chronotype distribution (ac- they are definitely evening type ( $n=21)$ and IT statcording to MEQ scores) with the answers to question ed that they are more evening types than morning 19 (which required self-assessment). Interestingly, it types but the questionnaire assigns them as interwas found that most of MMT identify themselves mediate, moderate morning or moderate evening as definitely morning type $(n=22)$, MET stated that types. That is shown on figures $4 A, 4 B$ and figure 5 .

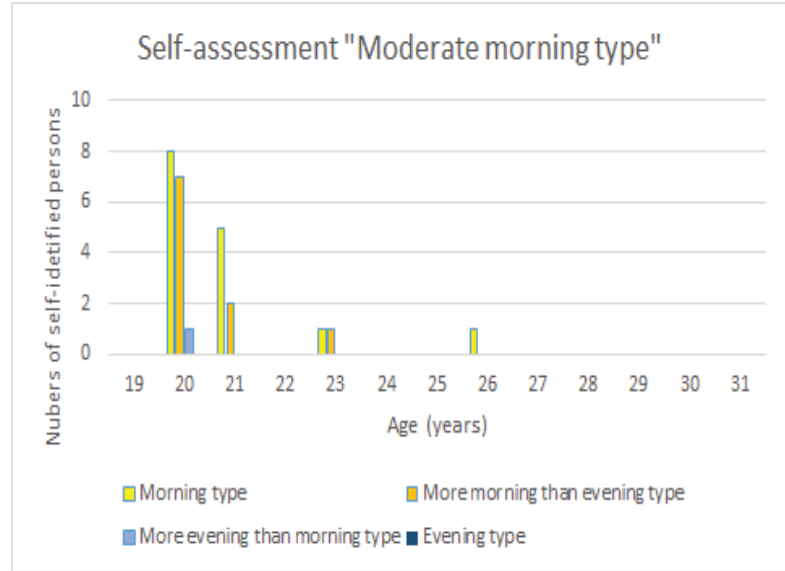

$A$

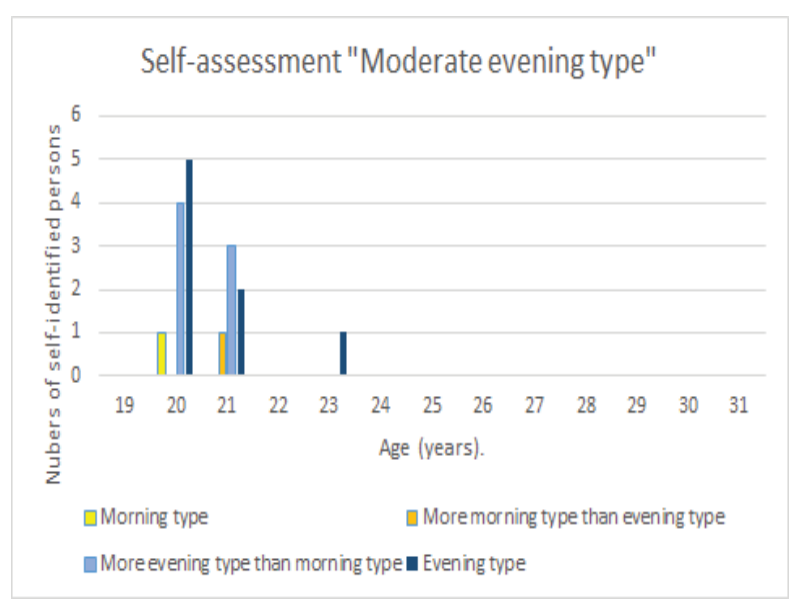

$B$

Fig.4 Self-assessment of moderate morning and evening types (according question 19) 


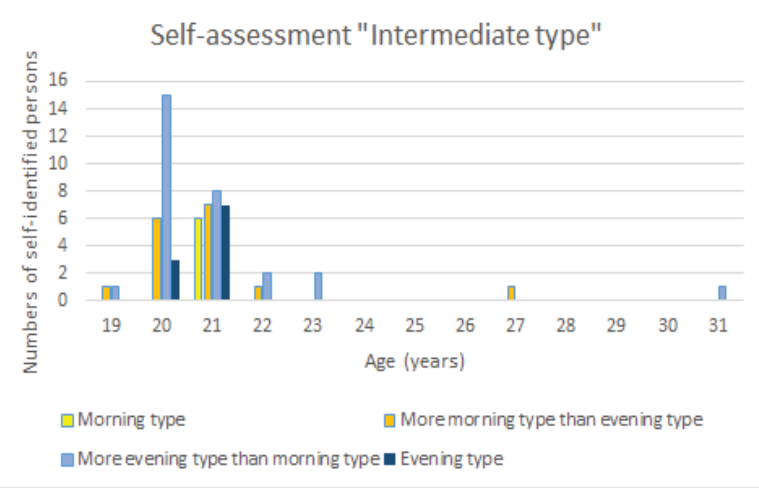

Fig.5 Self-assessment of intermediate type (according question 19)

\section{Discussion:}

The first aim of this study was the identification of chronotype in our sample. The results from the determination through MEQ showed that our sample of sport university students tended to be intermediate type and there were small number of students classified as moderate morning or moderate evening chronotype (these findings are in agreement with Vancova \& Pivovarnicek'16; Lastella et al'.16). In our sample definitely morning and definitely evening chronotype were not identified. It is possible students' lifestyle (work shifts and night life) and the fact that they have not got declared exact schedule of activities to have influenced the results. The sport activities, lectures and seminars are scheduled variously during the day (from early in the morning until evening hours). Based on that we cannot determine the exact time when students get up or go to bed (it is modified during the week according to different requirements). Age also has influence on chronotype which vary between pubescence and adolescence (Biss \& Hasher'12). The second aim was to compare self-assessment (question 19) to chronotype identified with MEQ. The result showed that there was misalignment between answers to the question and MEQ scores. That may influence the subjective feeling for right training time and may be due to age and lifestyle. As limitations to this study may be denoted that there were no chronotype assessment with more objective factor, no performance assessment and mixed gender group of participants. The objective determination of the chronotype is preferable but in most cases it is laborious, expensive, sometimes invasive, and must be performed by a specialist in chronobiology. Therefore, a questionnaire, although a subjective method, is always useful, inexpensive and sufficiently informative for a general assessment of a group's chronotype. In conclusion, we recommend determination of athlete's chronotype through a questionnaire to be done in any case, if possible. Also we propose coaches should always take into account the chronotype of athletes when they arrange the training schedules.

Acknowledgments: We are grateful to the sports students from National Sports Academy "Vassil Levski" for their participation in this study.

\section{References:}

Adan, A., Archer, S. N., Hidalgo, M. P., Di Milia, L., Natale V., Randler C. Circadian typology: A comprehensive review. Chronobiology International, 29(9): 1153-1175, (2012).

Adan, A. and Natale, V. Gender differences in Morningness-Eveningness preference. Chronobiology International. 19, 39-51, 2002.

Alexandrov A.S. Chronobiological Aspects in Endocrinology. Journal Endocrinologia, Vol. 3, no. 2, 4-15, 1998.

Baehr, E. K., Revelle, W. \& Eastman, C. I. 2000. Individual differences in the phase and amplitude of the human circadian temperature rhythm: with an emphasis on morningness-eveningness. J Sleep Res, 9, 117-27.

Biss, R. K., Hasher, L., 2012. Happy as a lark: morning-type younger and older adults are higher in positive affect. Emotion. Vol. 12, no. 3, s. 437-441.

Chtourou, H., Driss, T., Souissi, S., Gam, A., Chaouachi, A. and Souissi, S. The effect of strength training at the same time of the day on the diurnal fluctuations of muscular anaerobic performances. Journal of Strength and Conditioning Research. 26, 217-225, 2012.

Drust, B., Waterhouse, J., Atkinson, G., Edwards, B. and Reilly, T. Circadian Rhythms in Sports Performance - an Update. Chronobiology International. 22, 21-44, 2005.

Facer-Childs, E., \& Brandstaetter, R. 2015. The impact of circadian phenotype and time since awakening on diurnal performance in athletes. Current biology, 25(4), pp. 518-22.

Hill, D.W., Cureton, K.J., Collins, M.A. and Grisham, S.C. Diurnal variations in responses to exercise of morning types and evening types. The Journal of Sports Medicine and Physical Fitness. 28, 1988. 
Horne JA, Ostberg O. A self-assessment questionnaire to determine morningness- eveningness in human circadian rhythms. Int J Chronobiol. 1976;4(2):97-110.

Kareva R.I. (2012), Aviation psychology., Georgi Rakovski Military Academy, Sofia.

Kline, C.E., Durstine, J.L., Davis, J.M., Moore, J.A., Devlin, T.M., Zielinski, M.R. and Youngstedt, S. D. Circadian variation in swim performance. Journal of Applied Physiology. 102, 641-9, 2007.

Kunorozva, L. Diurnal preferences and sport performance: a subjective and genetic view. 2011. https://open. uct.ac.za/handle/11427/11263 (18.12.2016).

Lastella M., Roach G. D., Hurem D.C., Sargent C. Does chronotype affect elite athletes' capacity to cope with the training demands of triathlon? Living in a $24 / 7$ world: The impact of circadian disruption on sleep, work and health Australasian Chronobiology Society, Adelaide, Australia, 2010; 24(7): 25-28.

Lastella M., Roach G.D., Halson S.L., Sargent C. The Chronotype of Elite Athletes. Journal of Human Kinet- ics, Vol. 54/2016, 219-225.

Levandovski R., Sasso E., Hidalgo M.P. Chronotype: a review of the advances, limits and applicability of the main instruments used in the literature to assess human phenotype. Trends Psychiatry Psychother. 2013;35(1) 3-11.

Rae DE, Stephenson KJ, Roden LC. Factors to consider when assessing diurnal variation in sports performance: the influence of chronotype and habitual training timeof-day. Eur J Appl Physiol, 2015; 115(6): 1339-1349.

Roenneberg T, Kuehnle T, Juda M et al (2007) Epidemiology of the human circadian clock. Sleep Med Rev 11:429-438.

Slanchev P. (2014), Sports Medicine. Novi znaniya, Sofia. Vankova D. \& Pivovarnicek P. Identification of Chronotype and diurnal performance. Slovak Jurnal of Sport Science 1 (2016): 78-83.

W i r z - J u s t i c e A. How to measure circadian rhythms in humans. MEDICOGRAPHIA. 2007, VOL 29, No. 1, 84-90. 